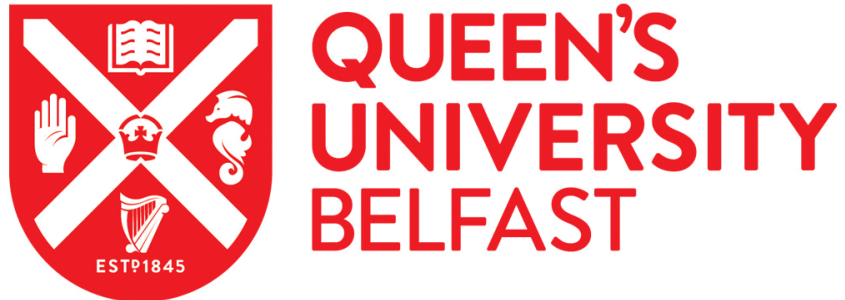

\section{Dimethicone barrier cream prevents infection of human skin by schistosome cercariae: evidence from Franz cell studies.}

Ingram, R., Bartlett, A., Brown, M., Marriot, C., \& And Whitfield, P. J. (2002). Dimethicone barrier cream prevents infection of human skin by schistosome cercariae: evidence from Franz cell studies. The Journal of parasitology, 88(2)(2), 399-402.

Published in:

The Journal of parasitology

Queen's University Belfast - Research Portal:

Link to publication record in Queen's University Belfast Research Portal

\section{General rights}

Copyright for the publications made accessible via the Queen's University Belfast Research Portal is retained by the author(s) and / or other copyright owners and it is a condition of accessing these publications that users recognise and abide by the legal requirements associated with these rights.

Take down policy

The Research Portal is Queen's institutional repository that provides access to Queen's research output. Every effort has been made to ensure that content in the Research Portal does not infringe any person's rights, or applicable UK laws. If you discover content in the Research Portal that you believe breaches copyright or violates any law, please contact openaccess@qub.ac.uk. 


\title{
DIMETHICONE BARRIER CREAM PREVENTS INFECTION OF HUMAN SKIN BY SCHISTOSOME CERCARIAE: EVIDENCE FROM FRANZ CELL STUDIES
}

\author{
R. J. Ingram, A. Bartlett, M. B. Brown, C. Marriott, and P. J. Whitfield \\ School of Health and Life Sciences, King's College London, Franklin Wilkins Building, 150 Stamford Street, London, SE1 9NN. \\ e-mail: phil.whitfield@kcl.ac.uk
}

\begin{abstract}
One approach to the prevention of schistosomiasis is the use of topical formulations to inhibit cercarial penetration of skin. A number of formulations containing either cercaricidal ingredients or components designed to inhibit penetration have been studied, but with variable results. Such studies have rarely considered the persistence of inhibitory effects through time, and to date, there have been no systematic investigations of barrier formulations. The aim of this study was to use Franz cells to investigate the effect of such barrier creams on the penetration of $S$. mansoni cercariae into human skin. The results show that a single application of a barrier cream based on dimethicone offers a high level of protection against penetration that is sustained for at least $48 \mathrm{hr}$.
\end{abstract}

Despite a number of successful control programs in Asia and the Americas (WHO, 1998), the estimated number of people infected with schistosomiasis has not dropped from 200 million and might, in fact, be higher (Hagan et al., 1998). In part, this is because of the ever-increasing number of cases in sub-Saharan Africa where control measures are still focussed on the limitation of morbidity (Doenhoff et al., 2000).

In this context, alongside health education and sanitation improvements (Gillett, 1985), the use of snail control measures (Perret and Whitfield, 1995), and hopes for the eventual development of a vaccine (Wilson and Coulson, 1998; Gryseels, 2000), the option of topical formulations to prevent cercarial penetration has a potential role in prevention of infection. Many substances have antipenetrant or repellent effects with respect to cercariae (Pellegrino, 1967). For example, the insect repellent $N, N$-diethyl- $m$-toluamide (DEET), blocks cercarial penetration when applied topically (Salafsky et al., 1999), but the drug was rapidly absorbed into the systemic circulation with subsequent loss of protection. Limited protection was reported after field trials of a topically applied lotion containing the molluscicide, niclosamide (Abu-Elyazeed et al., 1993). Formulations containing compounds that interfere with cercarial proteases have been tested with variable success in mice and on human skin from autopsy or surgical pathological specimens (Cohen et al., 1991; Lim et al., 1999).

The use of barrier formulations that prevent cercarial recognition of the skin, penetration, or both has not been systematically investigated, although early studies (reviewed by Pellegrino, 1967) showed that both motor oil and Vaseline gave some protection when applied topically. In a previous study (Bartlett et al., 2000), we have shown that a novel human skin model, using Franz cells, could be used to investigate the dynamics of cercarial penetration, and we noted that the system lent itself to the testing of topical formulations for the inhibition of cercarial penetration. Franz cells are 2-chambered glass enclosures that form an air/fluid-phase static diffusion system in which skin forms a partition between the 2 wells (Franz, 1975). The lower well contains tissue culture medium, and the upper well can be used to expose the epidermal surface of the skin to cercariae. The aim of the present study was to use this model to test the effects of a specifically formulated barrier cream on cercarial penetration.

Received 5 July 2001; revised 12 September 2001; accepted 12 September 2001

\section{MATERIALS AND METHODS}

\section{Topical agents}

Liquid paraffin; dimethicone 350; Vaseline (white soft paraffin); cream formulation prepared as follows: an emulsion was from dimethicone $350(100 \mathrm{~g})$, cetrimide (5 g), cetostearyl alcohol $(50 \mathrm{~g})$, liquid paraffin $(400 \mathrm{~g})$, and distilled water $(444 \mathrm{ml})$ by homogenization at 35 C. The formulation was stored at $4 \mathrm{C}$ until used. All chemicals were obtained from BDH (Poole, U.K.) except Vaseline which was a proprietary brand and cetostearyl alcohol which came from Croda Chemicals Ltd. (Goole, U.K.).

\section{The parasite}

Schistosoma mansoni was maintained in female NMRI strain laboratory mice and Biomphalaria glabrata essentially as described by Standen (1949). Cercariae for experiments were produced from snails, 4-6 wk after infection by stimulation at $28 \mathrm{C}$ with a bright light and were used within $2 \mathrm{hr}$ of emergence. All water for use with the snails and parasites was filtered through a carbon/resin cartridge (Prosep Filter Systems Ltd., Huddersfield, U.K.) to remove chlorine and heavy metals.

\section{Skin Culture}

Human skin from patients undergoing elective abdominoplasty was set up in Franz cells as previously described (Bartlett et al., 2000). Frozen $(-20 \mathrm{C})$ skin was defrosted, the underlying fat was removed, then the epidermis was cleaned with distilled water and dried. The skin was cut into $3.5-\mathrm{cm}$ diameter pieces and mounted between the 2 wells of each Franz cell with tissue-culture medium, i.e., $\mathrm{CO}_{2}$-independent medium, with $10 \%$ FCS and $1 \%$ antibiotic/antimycotic solution (GIBCO BRL, Paisley, U.K.) in the lower well of each cell. Control cells were set up with inert latex rubber membranes held in place with teflon O-rings. Cells were incubated with the lower chamber in a water bath at $38 \mathrm{C}$ such that the skin surface was held about $2 \mathrm{~cm}$ above the water level to give a skin surface temperature of about $35 \mathrm{C}$.

\section{Application of test substances to the skin}

To the epidermis of the skin, $0.1 \mathrm{ml}$ of test substance was applied; it was brushed to cover the whole surface uniformly. Cells were allowed to equilibrate for $1 \mathrm{hr}$ in the water bath before use to enable the formulation to spread into all folds and creases, and for the skin to become completely hydrated. Untreated skin and cells with inert membranes, to be used as controls, were similarly incubated before use.

\section{Experiment I}

Fifteen cells were prepared with skin and 3 with inert latex rubber membranes. Groups of 3 skin preparations were treated, as described above, with the cream formulation, dimethicone alone, liquid paraffin alone, and Vaseline. The remaining 3 cells with skin were used as controls (no treatment), and 3 inert membrane preparations were included as controls (no skin).

Cercariae were harvested and suspended in filtered water, and the numbers in 6,1-ml samples were counted to determine cercarial density; $5-8 \mathrm{ml}$ of suspension (to give a known number of about 1,000 cercariae 
TABLE I. Timing of addition of cercariae* to the Franz cells in Experiment II.

\begin{tabular}{|c|c|c|c|c|c|}
\hline \multirow{3}{*}{$\begin{array}{c}\text { Time } \\
(\mathrm{hr})\end{array}$} & \multirow{3}{*}{$\begin{array}{c}\text { Treated } \\
(3-5 \text { cells/group) }\end{array}$} & \multicolumn{4}{|c|}{ Controls ( 3 cells/group) } \\
\hline & & \multicolumn{3}{|c|}{ Skin, no treatment } & \multirow{2}{*}{$\begin{array}{l}\text { Inert } \\
\text { membrane }\end{array}$} \\
\hline & & A & B & $\mathrm{C}$ & \\
\hline 0 & $\begin{array}{l}\text { Skin painted with } \\
\text { whole formulation }\end{array}$ & & & & \\
\hline 1 & $\mathrm{ca}$ & ca & & & $\mathrm{ca}$ \\
\hline 24 & $\mathrm{ca}$ & $\mathrm{ca}$ & $\mathrm{ca}$ & & $\mathrm{ca}$ \\
\hline 48 & $\mathrm{ca}$ & $\mathrm{ca}$ & $\mathrm{ca}$ & $\mathrm{ca}$ & $\mathrm{ca}$ \\
\hline
\end{tabular}

* ca, cercariae added.

per well) was added to the upper well of all cells. Twenty minutes later, using plastic disposable pipettes, the suspensions were removed with gentle stirring, transferred to counting dishes, and observed microscopically for activity. Lugol's iodine was added to fix and stain the larvae, then whole cercariae and separated cercarial heads were counted.

\section{Experiment II}

Cells were set up with skin and with inert membranes, as described above; they were used as shown in Table I to test the continued efficacy of the formulation at 3 time intervals up to $48 \mathrm{hr}$ after application. Cercariae were added and recovered as before after $20 \mathrm{~min}$, then the skin or membrane surface was washed twice with $6 \mathrm{ml}$ of filtered water, and the washings were added to the counting dish. The condition of the cercariae was observed microscopically, then they were fixed with Lugol's iodine and counted. This experiment was repeated twice more with different populations of cercariae, skin from different individuals, and using a freshly prepared formulation each time. At 1 and $24 \mathrm{hr}$ after cercarial addition and the subsequent washing procedure, upper wells above skin preparations were sealed with plastic caps to maintain $100 \%$ relative humidity in the air above the skin. The lower wells were filled with fresh culture medium and the cells were maintained at $37 \mathrm{C}$.

\section{RESULTS}

\section{Experiment I}

All counts of heads plus whole cercariae recovered were expressed as percentages of the initial inoculum. The mean percentage of cercariae recovered was calculated for each group of Franz cells, and the results are shown in Figure 1. Statistical analysis of the results was carried out using arcsine transformation of the values to allow for nonnormal distribution of values expressed as percentages.

Whole cercariae recovered from inert membranes, skin treated with dimethicone, liquid paraffin, or cream formulation, were observed to be swimming actively and those with detached tails were crawling. No dead larvae were apparent, which indicates that none of the substances applied to the skin had any immediate toxic effects on the cercariae. Those recovered from Vaseline-treated skin were alive and vigorous, but clumped together and often covered with globules of Vaseline.

Consistently, only about $20 \%$ of the cercariae could be recovered from a cell with normal, untreated skin. That is, 20 min after application, about $80 \%$ of cercariae could not be dislodged from the skin with gentle stirring of the suspension. This was in striking contrast to the recoveries from cells with inert membranes, where up to $75 \%$ of cercariae were recovered. Cercariae exposed to skin treated with the cream formulation behaved as if the skin was an inert membrane, and up to $77 \%$ were recovered. Two of the components of the formulation,

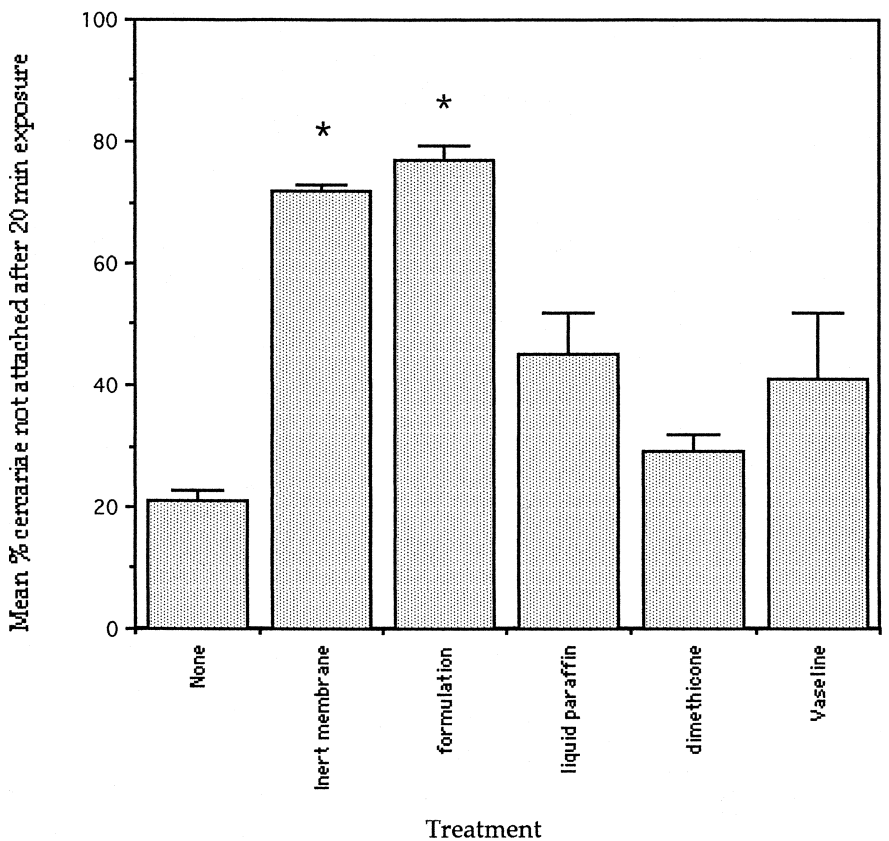

FIGURE 1. The mean percentage ( \pm SE) of cercariae recovered from groups of 3 Franz cells. $* P<0.05$ (Student's 2 -tailed $t$-test).

liquid paraffin and dimethicone, did not inhibit attachment significantly when compared with control, untreated skin (see Fig. 1). A similar, nonsignificant result was obtained with Vaseline.

\section{Experiment II}

The additional washing step included in the protocol in an attempt to improve the yield of unattached cercariae enhanced the recovery of cercariae from inert membranes from $75 \%$ to between 92 and $99 \%$ of the original inoculum. All cercariae recovered were alive when first observed, and whole larvae were swimming vigorously.

The results of Experiment II, in which only the complex barrier formulation was tested, are shown in Table II, which gives the means and standard deviations of the percentage of inoculum recovered. The table shows the combined results of all the experiments, and each value represents the mean of 3 experiments, each with 3-5 replicates per group for every time point, giving a minimum of 9 values. Recovery of cercariae from untreated controls was consistently between 15 and $25 \%$, even

TABLE 2. Results of the 3 replicate experiments to show the inhibition of attachment of cercariae to skin treated with the dimethicone formulation. The results show percent cercariae recovered ( $\pm \mathrm{SE})$.

\begin{tabular}{|c|c|c|c|c|c|}
\hline \multirow{3}{*}{$\begin{array}{l}\text { Time } \\
\text { (hr) }\end{array}$} & \multirow{3}{*}{$\begin{array}{c}\text { Treated } \\
(3-5 \text { cells/group) }\end{array}$} & \multicolumn{4}{|c|}{ Controls ( 3 cells/group) } \\
\hline & & \multicolumn{3}{|c|}{ Skin, no treatment } & \multirow{2}{*}{$\begin{array}{c}\text { Inert } \\
\text { membrane }\end{array}$} \\
\hline & & A & B & $\mathrm{C}$ & \\
\hline 0 & $\begin{array}{l}\text { Skin painted with } \\
\text { whole formulation }\end{array}$ & & & & \\
\hline 1 & $95 \pm 3$ & $19 \pm 1$ & & & $92 \pm 1$ \\
\hline 24 & $95 \pm 8$ & $24 \pm 2$ & $24 \pm 1$ & & $94 \pm 9$ \\
\hline 48 & $97 \pm 1$ & $20 \pm 1$ & $22 \pm 1$ & $21 \pm 1$ & $99 \pm 1$ \\
\hline
\end{tabular}




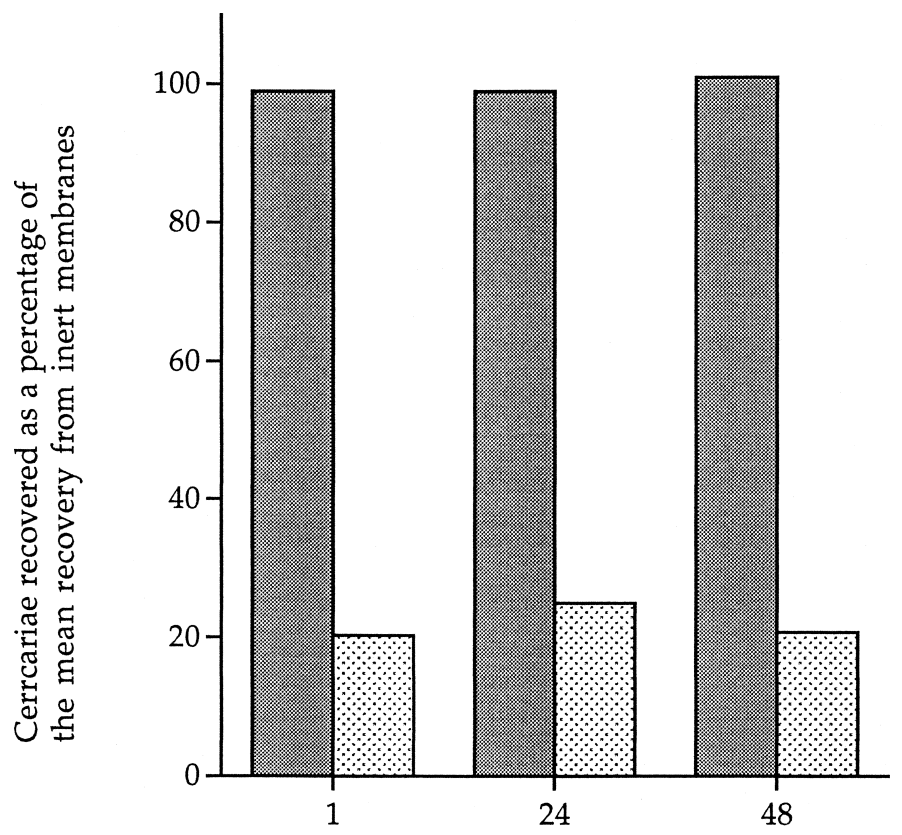

Time in hours

FIGURE 2. Cercariae recovered as a percentage of the mean recovery from inert membranes with (screen box) and without (dot box) the barrier formulation.

when the skin had been infected twice before; these values were, at all time points, significantly different from those for the formulation-treated skin (Student's $t$-test, $P<0.005$ ).

Cercariae exposed to the treated skin did not become irreversibly attached, and the numbers recovered were directly comparable to the numbers recovered from the inert membrane (Student's $t$-test, no significant differences, $P>0.1$ ). Figure 2 shows the results expressed as percentages of the mean recovery values obtained with inert membranes.

\section{DISCUSSION}

Experiment I showed that although Vaseline, liquid paraffin, and dimethicone oil appeared to give some levels of protection, these changes were not statistically significant when compared with control nontreated skin. The complete formulation, however, gave a very considerable degree of protection. This protective effect was investigated further in Experiment II, in which an additional washing step was included, which enhanced the recovery of cercariae from inert membranes to a mean of $95 \%$. The results showed that the formulation was an extremely effective antipenetration agent, with recoveries from treated skin not statistically different from those obtained using inert membranes. At each time point during the experiment, skin was washed when the cercariae were removed; yet, $48 \mathrm{hr}$ after initial application, with no further application of the formulation, treated skin was as unattractive to cercariae as was the inert membrane. This would suggest that the protective effect of the formulation is relatively resistant to water exposure and persists for at least $48 \mathrm{hr}$. Further work to quantify the persistence of this protection is currently underway.

Almost all previous work on antipenetrants has involved the use of cercaricidal or cercariostatic compounds, either applied directly to the skin or in a carrier substance, usually a cream or lotion. Little attention has been paid to barrier effects of the carrier alone. Lim et al. (1999), for example, have carried out studies to show that peptide and nonpeptide inhibitors of cercarial penetration enzymes, when applied to human skin in vitro, significantly reduce the numbers of cercariae subsequently found in the epidermis and dermis. Their results, however, also show that the vehicle they used to apply the inhibitors, $10 \%$ polyol-prepolymer in 50\% DMSO, had as significant an effect in preventing penetration of cercariae into human skin.

The mode of action of the formulation used in the present study is unknown. It is unlikely to be due to toxic effects of the constituent components because the cercariae recovered appeared to be swimming and behaving normally after exposure. The most likely explanation is that the formulation is acting as a mechanical barrier at 1 or more of the stages of the penetration process. Dimethicone will produce a hydrophobic layer on the skin surface and cercariae would be prevented from recognizing the skin if the formulation were masking normally attractive water-soluble components of the skin such as fatty acids (Shiff and Graczyk, 1994). Alternatively, the formulation could be preventing cercariae from attaching to the surface or, once attached, preventing them from penetrating.

The results of the present study provide sufficient in vitro evidence of the protective effect of a simple dimethicone cream to warrant future work of a clinical nature. Tests on laboratory models, such as mice, will reveal the extent to which our results can be duplicated in vivo.

The formulation is inexpensive to produce $(12.5 \mathrm{~g}$ could cover an average person and cost less than \$0.01). It is made of components routinely used in the pharmaceutical industry that have been subjected to exhaustive toxicity testing and have been passed as safe for topical use. All components are included in the GRAS list of the U.S. Food and Drug Administration and have been widely used as pharmaceutical excipients for many years. The lack of the need to include a novel bioactive compound means that the treatment should not be associated with unwanted side effects, and it could be used in field trials without further safety testing.

\section{ACKNOWLEDGMENTS}

This work was supported in part by a grant from the Sir Halley Stewart Trust. R.J.I. is in receipt of a research studentship from King's College London, University of London.

\section{LITERATURE CITED}

Abu-Elyazeed, R. R., J. K. Podgore, N. S. Mansour, and M. E. KilPATRICK. 1993. Field trial of $1 \%$ niclosamide as a topical antipenetrant to Schistosoma mansoni cercariae. American Journal of Tropical Medicine and Hygiene 49: 403-409.

Bartlett, A., M. Brown, C. Marriott, And P. J. Whitfield. 2000. The infection of human skin by schistosome cercariae: Studies using Franz cells. Parasitology 121: 49-54.

Cohen, F. E., L. M. Gregoret, P. Amiri, K. Aldape, J. Railey, and J. H. MCKerRow. 1991. Arresting tissue invasion of a parasite by protease inhibitors chosen with the aid of computer modelling. Biochemistry 30: 11,221-11,229.

Doenhoff, M. J., G. Kimani, And D. Cioli. 2000. Praziquantel and the control of schistosomiasis. Parasitology Today 16: 364-366.

Franz, T. J. 1975. Percutaneous absorption: On the relevance of in vitro data. Journal of Investigative Dermatology 64: 190-214. 
Gillett, J. D. 1985. The behaviour of Homo sapiens, the forgotten factor in the transmission of tropical disease. Transactions of the Royal Society of Tropical Medicine and Hygiene 79: 12-20.

Gryseels, B. 2000. Schistosomiasis vaccines: A devil's advocate view. Parasitology Today 16: 46-48.

Hagan, P., M. El Meleigy, and M. Traore. 1998. Schistosomiasis research: The end of the beginning. Parasitology Today 14: 392 394.

Lim, K. C., E. Sun, M. Bahgat, D. Bucks, R. Guy, R. S. Hinz, C. Cullander, AND J. H. MCKERROW. 1999. Blockage of skin invasion by schistosome cercariae by serine protease inhibitors. American Journal of Tropical Medicine and Hygiene 60: 487-492.

Pellegrino, J. 1967. Protection against human schistosome cercariae. Experimental Parasitology 21: 112-131.

Perrett, S., AND P. J. WhitField. 1995. Currently available molluscicides. Parasitology Today 12: 156-259.

Salafsky, B., K. Ramaswamy, Y. X. He, J. Li, and A. T. Shibuy. 1999
Development and evaluation of LIPODEET, a new long-acting formulation of $N, N$-diethyl- $m$-toluamide (DEET) for the prevention of schistosomiasis. American Journal of Tropical Medicine and $\mathrm{Hy}$ giene 61: 743-750.

ShIFF, C. J., AND T. K. GRACZYK. 1994. A chemokinetic response in Schistosoma mansoni cercariae. Journal of Parasitology 80: 879_ 883.

StAndEN, O. D. 1949. Experimental schistosomiasis II: Maintenance of Schistosoma mansoni in the laboratory, with some notes on experimental infection with $S$. haematobium. Annals of Tropical Medicine and Parasitology 43: 268-283.

[WHO] World Health Organization. 1998. Report of the WHO informal consultation on schistosomiasis control. Schistosomiasis and Intestinal Parasite Control Planning and Technical Guidance Ref: CDS/CPC/SIP.99.2; Geneva, Switzerland.

Wilson, R. A., AND P. S. Coulson. 1998. Why don't we have a schistosomiasis vaccine? Parasitology Today 14: 97-99. 